\title{
An Examination of Information Technologies Changing the Shape of Sport
}

\begin{abstract}
Rene Leveaux
University of Technology, Sydney, Australia

Correspondence should be addressed to: Rene Leveaux;rene.leveaux@uts.edu.au

Received date:9 September 2015; Accepted date:31 August 2016; Published date: 2 January 2017

Academic Editor: Jon W. Beard

Copyright (C) 2017. Rene Leveaux, Distributed under Creative Commons CC-BY 4.0

Abstract

Today's sport is changing due to various factors external to the sport which impact on the shape of a sport. The focus of this study was to examine changes due to the uses of information technologies. A series of interviews $(n=36)$ was conducted across three areas: (1) Professional players and coaches of professional players (2) amateur players and coaches at amateur levels and (3) spectators to gain an understanding of the applications of information technologies in sport. The findings indicated that players at the professional level are using various technologies such as GPS vests to manage workload and reduce risk of injury. With amateur level sport, technologies are not as prevalent and the possible introduction of technology was surprisingly not considered as imperative. Spectators, in general, considered that the introduction of technologies changed the dimensions of their involvement both positively and negatively. The findings provide a basis for further studies and possible trials with additional technologies to further assist the athlete and coaches and innovatively further enhance the spectator's experience.
\end{abstract}

Keywords: Innovation, informati on technology, sport

\section{Introduction}

There is little doubt that advances in technology impact most people's everyday lives - from smartphones and tablets, to cars and household appliances. This also includes many aspects in the sporting environment. However it beckons the question: Have the advances and introductions of sporting information technologies helped to improve the quality of the sport from the perspective of participating and of spectating?

Technology in sport not only aids to improve decision making by the officials (Leveaux 2010) but with the application of relevant technologies helps in the preparation of the athlete, and additionally provides avenues for innovative experiences for the spectator. Developments in innovative, sports related information technologies have produced an array of products aimed at enhancing athletic performance. The health of an athlete can be observed, injuries treated and training performance monitored, through the production of modern sporting technologies such as heart rate monitors, body-fat monitors, GPS vests and various tracking devices for athletes.

There are many sports and sports related activities, some of which may only require 
very little physical activity, for example, chess. Others may require extensive physical activity of well-conditioned athletes. The term "sport", for the purposes of this study, relates to a physical activity conducted and governed under a formal set of rules and regulations administered by a governing body.

To focus on the research, the interviews conducted were based on competitive sport and the technologies that have been conceived to enhance performance and to improve the game. The technologies researched were chosen because these have generated considerable debate in recent years. The sports were selected due to the relatively high technology usage from both the player and spectator point of view.

\section{Research Methods}

The study was conducted through discussion groups and interviews. The advantage of doing qualitative research with this study was that it allowed greater understanding of the interviewees' personal constructs and experiences. All participants in the study were fully informed and voluntarily consented to their involvement. Participants were also free to withdraw from the research without giving reason or justifying their decision at any time, if they so wished.

Following a pre-interview group discussion $(n=5)$ a general interview script was developed based on issues derived from comments and points raised and to allow for semi structured interviews. McCracken (1988) discusses how interviews can draw on the past as well as the present to extract a deeper understanding of an issue than a simple survey type inquiry. Erlandson (1993) states that the use of semistructured interviews allows the investigator to ask respondents for facts as well as gathering opinions, and as suggested by Patton (1990), this allows other related topics to emerge. The same main format of questioning was employed in all interviews.

The interviewed subjects were solicited through email or through chain sampling. Chain sampling "identifies cases of interest from people who know people who know people who are information-rich, that is, good examples for study, good interview subjects" (Patton, 1990). All of the volunteers were chosen for interview on the basis of availability, suitable experience and use or knowledge of technology(s) used in their chosen sport. Erlandson (1993) suggests that this technique of "purposive sampling" is preferred to random or representative sampling because the major concern of the researcher is to maximize discovery of the problem and the heterogeneous patterns that occur within the context of the particular study. Semi-structured interviews were conducted at a location that suited the interviewee and in general lasted approximately 40 minutes.

All the interview participants had differing involvements in sport up to and including international competition. The professional players $(n=9)$ and coaches $(n=3)$ have international experience either at the national level or are on contract to professional sports clubs or franchises. The amateur players $(n=11)$ all had in excess of 20 years' experience in the specific sport and had at some stage during this period competed at a semi-professional level. The amateur coaches $(n=5)$ have held coaching positions at differing levels from junior competition to amateur representative level and were all currently coaching. The spectators $(n=8)$ interviewed were avid fans of their chosen sport, and either watch their sport and team live, on the television or both.

The interview participants were drawn from team and individual sports - rugby (both rugby union and rugby league), football (soccer), and athletics (track and field).

The focus of the questions centred on the views, if any, participants had in relation to the uses of information technologies and the impact of the use of the information technologies in relation to their individual and / or team preparation for competition; and in relation to spectating in their sport. Any views or opinions in relation to another sport, or information technologies not employed by their sport, were not included as these data were not the focus of 
the study. Participants were also asked about their own adaptation to the use of the technologies, changes to their own practices leading up to a match, during and after a match. Their personal viewpoints on information technology, in relation to levels of application and introduction, what they enjoyed or did not enjoy with the use of the technology(s) employed in the sport, and what aspects they had or had not appreciated were also explored. The interviews were recorded and transcribed for analysis. Follow-up phone calls were made to two respondents where clarification or further investigation was required.

\section{Findings and Results}

There was a time when technology had very little impact on sport (Rosandich 2008), however now it is playing a significant role in both competition and training. Not long ago sportspeople simply trained hard and if they felt it necessary or perceived to be fatigued, they would rest or cease the training session. There was no technology to determine whether or not a sportsperson was fatigued and needed to stop training to avoid injury or over training, or if they had not trained at a sufficient level and needed additional training. Sportspeople are now using technologies to prepare for competition and assist in the determination of the suitability of the training prescription and the levels of their training output. Additionally, sporting equipment is repeatedly undergoing research and development to improve performances on the sporting field, at both the amateur and elite levels, and has had a noticeable impact on most facets of sport (Rosandich 2008).

Information technology is additionally finding its place in the officiating of a match or competition. For example, prior to the implementation of information technologies, sports such as tennis relied on the eye of an umpire to determine if a ball was in or out. In today's game, technology called 'Hawkeye' is widely used to ascertain if the ball is in or out. Hawkeye has a margin of error of 3.6 millimetres; therefore it's very accurate and hence accepted. It uses several high-speed cameras that insert data into a computer that replicates the ball's path and pinpoints its landing spot (Jenkins 2014).

\section{Professional Sport}

In recent years, the use of the technology by professional sportspeople has increased dramatically. This attitude shift has coincided with changes in technology. Rosandich (2008) notes a good example of changes in professional sports is the use of "smart" apparatus that feature sensors to measure performance indicators. Almost all professional athletes have their performance evaluated as part of their training regimen. This technology can be used for the evaluation of strength and conditioning from stress (load) testing to more advanced testing such as cardiovascular assessment.

In many professional sports these days athletes are wearing heart monitors in every training session (Ligaya 2014). The athletic performance co-ordinators / conditioning staff use this technology to record and trace each player's workload and heart rate during training. Storing these data allows the clubs coaches and doctors to determine when to adjust the players training program during training sessions or to remove them from the training field completely to avoid injury. This is a change in the acceptance to use of technology by the players, where players considered technology more of a hindrance; to now, where technology is accepted to assist in the performance of the player.

Ligaya (2014) states that wearable technology, such as heart rate monitors, has become mainstream at the elite level. Athletes are continually striving for an edge over an opponent, and sensors which can gather detailed information on heart rates, speed and workload can assist to improve athletic ability and performance, physically stronger or able to recover quicker than their opponent. Novellino (2013) mentions that Adidas has already created shirts with sensors embedded into them that measure an athlete's performance with data sent to the coaching staff in real time. The information obtained includes speed, distance, acceleration and deceleration and heart rate. The sensors 
send encrypted radio frequency signals to a central system, which in turn connects via a web server to a tablet such as iPad via WiFi where real time metrics are displayed. Technology has changed the playing equipment that athletes wear in both training and competition. In the past, athletes would wear items such as loose cotton shirts, but now they are wearing specific clothing which is not only comfortable but also contains built in technology which increases or is designed to enhance performance.

Muro (2011) notes English Premier League heavyweight Arsenal started wearing GPS vests in the pre-season of the $2011-2012$ season. These devices record the activities of the players on the football field. They also assist to measure the player's load by recording the heart rate and the distance travelled. The results are used to indicate whether the player is fatigued and therefore needs a change in training regime. Such changes to fatigued player minimises the risk of injury and aids in the prevention of injuries. This is a significant change in training which has been brought about by technology. In years gone by, preseason training consisted of players running long distances and training very hard, often until they were physically sick, with no devices used to monitor training protocols such as fatigue levels. However, today the players accept technology at the professional level, and understand that by observing and acting on the data recorded, they have the ability to prevent injuries and improve the athlete's training output which results in making the player available for more competition matches and with less risk of an injury, as noted by one interviewee.

The use of training vests and other training technologies is greatly helping us monitor our players. Since using them and monitoring our players, the incidences of players being overtrained have dropped dramatically, as has fatigue related injuries.

Athletes are realizing that the use of technology can assist them in gaining an edge over an opponent. The acceptance of technology has more or less become commonplace amongst the professional athletes. Rosandich (2008) states that the computer, and the software used, is the most essential element in the new sporting world and is essential to the success of the modern athlete.

Information technology at the professional level has not only changed the way the athletes train and play, but how the game is officiated (Leveaux 2012). Football, a sport very rich in tradition, has always moved with the times. For example, goal line technology was introduced in 2014 at the sports showpiece event, the World Cup. This is a considerable change in the sport. In the past, there have been many controversies in the sport with the officials making wrong decisions. Due to the increases in the changing pace of sport, there are greater demands and expectations on the on-field officials to not only be fitter so as to be able to keep up with the play, but to also be in a continually greater state of preparedness to make quick and correct decisions in often shorter time spans.

German produced GoalControl was the system used at the 2014 World Cup in Brazil. It operates by placing 14 high-speed cameras around the stadium, with seven pointed at each goal. These cameras track the trajectory of the ball and detect whether the ball has crossed the goal line or not (Gibbs 2014). The cameras are connected to a computer system which traces all moving objects on the field and filters out everything except the ball. The system knows the position of the ball with a precision of several millimetres within the coordinates of the field. As the ball passes the goal line, the computer system sends a vibration to specialized watches being worn by the match officials (GoalControl 2014). GoalControl has removed a lot of the guess work when it comes to determining if the ball has crossed the line or not. All stakeholders in the games can now be assured that when the decision has been made to award a goal, it is the most accurate decision available (Bernard 2014).

\section{Amateur Sport}

The use of technology at the amateur level is nowhere near as profound as the professional level. Rosandich (2008) notes the use of technology in sports equipment 
is unevenly applied, and not universal. Professional sporting organizations usually have far greater access to financial resources and subsequently access to a team(s) of experts providing them with technology such as the GPS vests and these experts can monitor the results.

The amateur sportsperson could buy the same or similar equipment themselves, however it's expensive and they would also need to interpret the results themselves. It was also found that having the human resources to manage the technology additionally became an issue.

It would be great to have access to all the technology being used in the professional clubs, but our club simply does not have the resources to pay or even manage the technology. We bought a laptop and game analysis software a couple of years ago, but couldn't find anyone to run it. So it's just been sitting in the cupboard for the last few years.

Amateur athletes may use technology in an attempt to improve themselves by tracking sleeping patterns, distance travelled as well as food and liquid intake. However, when it comes to the actual game itself they feel the use of some of the more sophisticated technologies, such as implementing goal line technology, is not a pressing concern and that money could be put to better use. Implementing technology such as goal line technology at the amateur level in the game of football would be virtually impossible. The costs would in all likelihood be beyond the reach of most amateur clubs and could not be justified. Surprisingly, the question of technology at the amateur level is one of non-acceptance. The players interviewed agreed that the introduction of goal line technology would benefit the match officials as it is one less thing to worry about. However, they agreed the money could be put to better use if spent elsewhere. The coaches had a similar response. Some coaches thought the amateur game should be as closely aligned

with the professional game as possible, and therefore support the introduction of goal line technology at the amateur level.
However, others thought, just like the players, that the money should be spent elsewhere as decisions made at the amateur level aren't scrutinised as much. In addition, it may create more issues for the officials as players and coaches may argue the decision made is wrong.

\section{It would be ideal to have the amateur game refereed and played in the same type of environment as the professional players, but there just isn't the funds around to do so; and if there were the funds available, they would most likely be better spent elsewhere in the club.}

As an alternative to the commercial applications, there is the option of using low cost applications and / or freeware. While not offering the same levels of analysis, they do provide the amateur clubs, coaches and athletes some base level analysis and management at both the team and game levels. For example, one of the more recently released is an app that can be run on the iPad or iPhone called SportsBoard (Coulam 2014). This application can be used to grade players and has assisted with the selection of players into teams, or for selecting athletes for individual competitions. Data can additionally be easily transferred into other applications such as Microsoft Excel for further analysis.

Not only has technology transformed the way people participate in sports but it has also changed the way people exercise or train in the gym. Athletes in the past were restricted to outdoor activities or gyms having limited exercise equipment (barbells, dumbbells, etc). Nowadays, gyms offer a vast array of training equipment using including technology driven aerobic equipment such as treadmills, bikes, steppers, rowing machines, etc., which now provide various training options from a variety of resistances to simulating different types terrains, are personally programmable and additionally provide forms of entertainment while the athlete trains. Treadmills these days have televisions built-in with a variety of free to air and pay TV channels available to watch.

Additionally, there have been significant developments to the clothing worn in 
competition and in training. Advances in sporting apparel have been designed not only to improve performance, but to also enhance the wearer's experience. For example, 'dri-fit' shirt have been designed to draw an athlete's sweat from the body where it is evaporated (Nike 2014) while also allowing the athlete a greater range of motion due to the specifically designed elastic-like fabric.

Popper (2014) notes there have been significant changes in technology when it comes to the clothes people wear to the gym. He notes there are clothes that are wired with sensors that track the motion in the muscle tissue and track how hard the body is operating. As an athlete is training an electric signal is produced with the tightening of muscle tissues and then this signal is recorded. The sensors are knitted into the clothes and are washer and dryer safe. The technology works by looking how muscle groups are working together. If you are doing an exercise the technology can see the muscle tissues that are exercising the most and warn you if one muscle group is hindering another.

\section{Spectators}

The rapid advances in technology have greatly changed the spectator experience, and now offer the spectator numerous options. The technology has significantly changed the viewing experience. While television broadcasting of sports live has been commonplace for more than 40 years, spectators now have the options to watch, listen or read about the game live using mediums such as Internet streaming, Internet radio and applications on smart devices. This allows spectators to be anywhere in the world, in any time zone, and still be able to watch, listen or read about a specific sporting event as it occurs in real time.

For spectators, technology is now also filtering down to the amateur level. Little League Baseball has a broadcasting arrangement with a video service provider. The company places a camera behind the fence of the catcher which is then live streamed using the Internet. The little leagues do not pay for this service. The service provider's revenue is generated through subscriptions to the service to watch the games (Cohen 2009). This allows parents or distant relatives who are unable to watch the game live, an avenue to still watch the game in real time. Spectators can be in a different time zone but still watch, for example, their child's game live.

Some technologies, while being used as part of game management, are also being used to enhance the user experience. Tennis has been using the Hawk-Eye technology to review decisions when being challenged by players. Vision processing is used to identify the centre of the ball in each television camera. A 3D position of the ball is created as each camera triangulates the data. This information is used to calculate the exact position the ball made with the court and it takes approximately 5 seconds for the system to have a decision on a challenge. As the stadium screens the Hawk-Eye decision to show if the ball was in or out, the spectators are also there watching the decision courtside or on broadcast. The Hawk-Eye system has brought a different dimension to the game (Hawk-Eye 2014) for spectators. Jenkins (2014) states that as well as allowing spectators to watch replays with the players and officials, Hawk-Eye removes all controversy in a matter of seconds.

It can be argued that the introduction of technologies to challenge the referee's decision is not always a positive. If the referee officiating the match is uncertain of a decision, the match will stop and go to the video referees running the technology to confirm, overturn or make a decision. The video referees have access to a television screen(s) where they can watch replays of the event in question from differing angles. Once they have reached a decision they advise the match referees and the game continues. This has been a considerable change in sports using video referees. While the video referees are there to ensure the correctness of a decision, the process can be disruptive to the flow of the match and in some cases the video decision may not be correct due to the limitations in which a decision made be challenged.

The video referee is probably overall a good thing. Most of the 
time they do get it right, but there are times when they do get it wrong; and that's not good and luckily not that often. It just depends on what's on the video. It's also frustrating when there is a fast match and the referee goes to the video and we are waiting for a decision. It slows everything down and disrupts the tempo of the match. There should be a way to speed the process up to minimise the impact on the flow of a match.

The introduction of goal line technology in football has caused much debate. Goal line technology is designed to assist in keeping the integrity of football through the correctness of scoring goals. TV viewers get to see just how close the ball is to crossing the line which enhances the experience of the spectators (Ryall 2012).

Ryall (2012) stated that the governing body of football (FIFA) initially gave eight reasons why they were against the introduction of goal line technology. Interestingly FIFA's fourth reason was "Fans like to debate the controversial decisions".

As a result of technological changes, spectators can now witness sport in ways that previously were not possible with technologies such a Spidercam. This has resulted in a unique viewing experience taking the spectator into the middle of the playing arena. Dorries (2013) explains that Spidercam was successfully used in the game of cricket in the summer of 2012 2013 and used for the first time in rugby league in March 2013 and now is fairly commonplace in major sporting events. The camera is perched over the sporting field by a network of pulleys and cables. This state of the art technology takes spectators directly above the play, where they will almost feel as though they are part of the game.

\section{Discussion}

This study has shown how the introduction of information technologies has changed sport. The changes impact all levels of the sport's stakeholders - from the professional level all the way down to that of the spectator. Technology at the professional level has not only changed the way the athletes train and play, but also changed how the game is officiated. Players are wearing GPS vests while they train and tracking devices during matches which help to manage their workload and therefore reduce the risk of injury due to fatigue. The use of the video referee has changed the way the games are being officiated. However the use of the video technology has caused debate both among the professional players and the spectators. Although they agree it has helped to get the correct result, it is felt that the use of the video technology is overused and hence slows the match down, which in turn frustrates both the players and spectators.

Possibly one of the more surprising findings of the study is that both the amateur players and coaches felt the introduction of information technologies to the amateur level sports, such as goal line technology in football, is not necessary, as the majority considered that available funds would be better spent elsewhere in the sport at that level. If the technology were to be introduced at that level of competition, they all felt it would somehow make the life of the referee a little easier.

The introduction of some information technologies has definitely seen improvements in some sports. Decision making technologies such as Snicko and Hawk-Eye have been seen as a positive for the games of cricket and tennis respectively. Because there is a limit on the amount of times in a game these technologies can be used, and are computer generated and not relying on human interpretation, they were seen as positives to these sports as delays in a match were minimal. Additionally, these technologies bring a different dimension to the spectators as they are now considered to be more informed in relation to the decision making process.

\section{Conclusion}

This work shows that differing information technologies have been introduced into the sport with differing levels of success. Information technologies are now reasonably well received as part of competitive sport especially at the professional levels. In most instances at the 
professional level, information technology promotes a more attractive sport for both the spectators and the players due to more transparency in on-field decision making, as well as increasing the potential of athletic ability and performance of the game's participants.

\section{Further Research}

These results are drawn from only a limited sector of today's sports, and only from those which the authors had immediate access to. The findings of this study should be considered in that light. The study does lay foundations for further, more detailed research to be constructed to examine the potentiality of technology and its impacts on sport and sports stakeholders. The results of such studies would enable sports administrators to introduce technologies confidently with a more complete understanding of the impacts on the sport and its stakeholders

\section{References}

1. Bernard, S. (2014), Inside The World Cup's Cutting-Edge Goal-Line Technology, Made By A German Startup, BostInno, [Online], [Retrieved November 23, 2014], <http://bostinno.streetwise.co/2014/06/1 4/world-cup-2014-goal-line-technologysystem-by-goal-control-how-the-worldcups-goal-line-technology-works/>

2. Cohen, R. (2009), Amateur sports go high-tech, too, The Sydney Morning Herald, [Online], [Retrieved November 23, 2014], < http://news.smh.com.au/breaking-newstechnology/amateur-sports-go-hightechtoo-20090917-frzn.html>

3. Coulam, K. (2014), The evolution of sports through technology: How SportsBoard is changing the game, The Fields of Green, [Online], [Retrieved December 2, 2014], <http://thefieldsofgreen.com/2014/09/23 /the-evolution-of-sports-throughtechnology-how-sportsboard-is-changingthe-game/>

4. Dorries, B. (2013), Channel Nine to introduce Spidercam to rugby league coverage this season, The Daily Telegraph, [Online], [Retrieved December 07,2014], <http://www.dailytelegraph.com.au/sport /nrl/channel-nine-to-introduce-spidercamto-rugby-league-coverage-thisseason/story-e6frexnr-1226589499694>

5. Erlandson, D. A. (1993), Doing a Naturalistic Inquiry: A Guide to Methods, Newbury Park, CA.,

6. Gibbs, S. (2014), World Cup goalline technology: how does it work?, The Guardian, [Online], [Retrieved November 23, 2014\}, <http://www.theguardian.com/technology /2014/jun/16/world-cup-goallinetechnology-football-brazil-2014>

7. GoalControl. (2014), About GoalControl4D, [Online], [Retrieved 23 November 2014],

<http://goalcontrol.visualseven.de/en/pro ducts/goalcontrol-4d.html>

8. Hawk-Eye. (2014), Hawk-Eye, [Online], [Retrieved November $25 \quad$ 2014], <http://www.hawkeyeinnovations.co.uk/p age/sports-officiating/tennis>

9. Jenkins, B. (2014), How the Hawk-Eye instant-replay system has changed tennis, Sports Illustrated, [Online], [Retrieved November 22, 2014], <http://www.si.com/tennis/2013/08/26/ tennis-innovations-hawk-eye>

10. Leveaux R. (2010) 'Facilitating Referee's Decision Making in Sport via the Application of Technology" Communication of the IBIMA 2010 (1-8)

11. Leveaux, R. (2012) Decision making Technology for Olympic Taekwondo Referees. 2012 Pre-Olympic Congress on Sports Science and Computer Science in Sport. Liverpool United Kingdom July 24252012

12. Ligaya, A. (2014), High-tech sports pros seek edge over rivals with wearables, Financial Post, [Online], [Retrieved November 22, 2014], <http://business.financialpost.com/2014/ 10/23/high-tech-sports-pros-seek-edgeover-rivals-with-wearables /?_lsa=948b0fc8>

13. Lincoln, Y. and Guba, E. (1985), 
Naturalistic Inquiry. Newbury Park, CA

14. McCraken, G. (1988), The Long Interview, Newbury Park, CA

15. Muro, G. (2011), Wenger - Why players are wearing GPS vests, Arsenal Football Club PLC, [Online], [Retrieved December 02, 2014],

<http://www.arsenal.com/news/newsarchive/wenger-why-players-are-wearinggps-vests>

16. Nike. (2014), What Is Nike Dri-Fit?, [Online], [Retrieved December 06, 2014], < http://help-en-

us.nike.com/app/answers/detail/a_id/204

/ /what-is-nike-dri-fit\%3F>

17. Novellino, T. (2013), Adidas wearable tech makes for smarter soccer, Upstart Business Journal, [Online], [Retrieved November 24, 2014], <http://upstart.bizjournals.com/companie s/rebel-brands/2013/07/24/adidaswearable-tech-makes-sportssmart.html?page $=$ all $>$

18. Patton, M. (1990) Qualitative Evaluation and Research Methods (2nd ed.). Thousand Oaks, CA: Sage

19. Popper, B. (2014), These high-tech gym clothes look inside your muscles to analyze your workout, The Verge, [Online], [Retrieved December 06, 2014], < http://www.theverge.com/2014/8/12/59 92297/athos-fitness-wearableelectromyography>

20. Robinson, W.S. (1951), The Logical Structure of Analytical Induction. American Sociological Review, 16: 812-818

21. Rosandich, T.J. (2008), Sports Equipment and Technology, The Sport Journal, [Online], [Retrieved November 22, 2014], http://thesportjournal.org/article/sportsequipment-and-technology/>

22. Ryall, E. (2012), 'Are there any good arguments against goal-line technology?', Sport, Ethics and Philosophy, vol. 6, no. 4, pp. 439-450.

23. Wallace, E. (2009), The Role of Technology in Sport, University of Elster, [Online], [Retrieved November 13, 2014], < http://www.ulster.ac.uk/scienceinsociety/ technologyinsport.html>

24. Williams, R. (2014), "Fans give AFL judiciary and goal review the thumbs down", Herald Sun, [Online], [Retrieved November 30, 2014], <http://www.heraldsun.com.au/sport/afl/ fans-give-afl-judiciary-and-goal-reviewthe-thumbs-down/story-fni5f22o1227020182167 ?nk=0251c520b48505f06 a3fa6e5d8638921 